\title{
Very short-term visual memory for size and shape
}

\author{
JOHN PALMER \\ University of Washington, Seattle, Washington
}

\begin{abstract}
Very short-term visual memory is often studied using partial report of alphanumeric characters to measure cue-delay effects. Although such cue-delay effects have been extensively studied, few studies have considered noncharacter stimuli, and those few were mixed in their conclusions. Here, three experiments pursued the cue-delay effect for discrimination judgments of noncharacter stimuli, such as the length of a line or the shape of a rectangle. In the line-length experiment, four lines were presented, with an auditory cue indicating one of the lines, and then a single line was presented. The observers discriminated between the length of the cued line in the first display and the length of the single line in the second display. The cues were presented either before or after the four-line stimulus. A cue-delay effect was found for these stimuli. Lengthdifference thresholds nearly doubled for cues presented $500 \mathrm{msec}$ after the first display, compared with cues presented $500 \mathrm{msec}$ before. A further experiment revealed a similar cue-delay effect for shape discrimination of rectangles. One reason this effect may not have been reported reliably is that it is largely evident for precues, and most previous studies used primarily postcues. In summary, the cue-delay effect is general to noncharacter stimuli.
\end{abstract}

Experiments on very short-term visual memory have often demonstrated a rapid loss of information over time intervals of less than a second (Sperling, 1960). This effect has been studied primarily with stimuli consisting of alphanumeric characters; only a few studies (e.g., Treisman, Russell, \& Green, 1975) have examined noncharacter stimuli. Furthermore, some investigators (e.g., Haber, 1983) have criticized the existing studies and argued that the rapid loss of information does not generalize beyond character stimuli. To better resolve the question of generality, the present study measured cue-delay effects for noncharacter stimuli.

\section{Background}

Interest in very short-term visual memory was awakened by the introduction of the partial-report task (Sperling, 1960). In such tasks, a multiple-row display of letters is presented, followed by an auditory cue indicating which row is to be reported. Report accuracy is measured as a function of the delay between stimulus offset and cue onset. With increasing cue delay, there is a decrease in the probability of a correct report. This cuedelay effect has been replicated often (e.g., Averbach \& Coriell, 1961; Chow, 1985; Treisman et al., 1975). The cue-delay effect may be accounted for by several different hypotheses. It may represent forgetting from a very short-term visual store (Rumelhart, 1970; Sperling, 1969); it may represent forgetting of associations within a post-

I thank Vincent Di Lollo, Dave Irwin, Beth Kerr, Lester Krueger, Delwin Lindsey, Geoff Loftus, Mark Reinitz, Steve Yantis, and Zelda Zabinsky for comments on early versions of the manuscript. I also thank Ray Slettevold for help in conducting the experiments. This work was supported in part by a grant from the Graduate School of the University of Washington (PHS RR-07096). Correspondence should be addressed to John Palmer, Department of Psychology, NI-25, University of Washington, Seattle, WA 98195. categorical store (Coltheart, 1980; van der Heijden, 1984); or it may represent a side effect of completing perceptual processing (Di Lollo, 1980; Haber, 1983; Schulz, 1980).

As a step toward evaluating these alternative hypotheses, it is useful to establish the generality of the cue-delay effect. First, the method of cuing can be varied. In addition to an auditory cue to visual location, cues can include visual location, color, brightness, size, and shape (e.g., Turvey \& Kravetz, 1970; von Wright, 1968). These studies indicate that any simple perceptual attribute can be used as a cue (but see Duncan, 1983; Merikle, 1980). Second, the procedure used to demonstrate the phenomenon of persistence can be varied. Alternative procedures include subjective persistence, temporal integration, and study-test paradigms (e.g., Di Lollo, 1980; Farrell, 1984; Meyer \& Maguire, 1977; Phillips, 1974). However, Coltheart (1980) and others (e.g., Irwin \& Yeomans, 1986) have argued that these alternative paradigms measure something different from what is measured by partial report. Therefore, I will restrict my attention to partialreport-like tasks. Third, the kind of information tested can be varied. Using partial report of characters, measurements have been made of cue-delay effects for both character location and character identity (e.g., Chow, 1986; den Heyer, 1972; Dick, 1969; Mewhort, Campbell, Marchetti, \& Campbell, 1981; Townsend, 1973). These studies have proven to be controversial, and there is disagreement about whether the cue-delay effects are similar for the two kinds of information.

There is a fourth generalization: Stimuli can be something other than characters. Studies attempting to generalize cue-delay effects to noncharacter stimuli are the focus of this article.

Perhaps the most comprehensive study using noncharacter stimuli was done by Treisman et al. (1975). They 
studied cue-delay effects using shape and movement judgments of circular dot patterns. The shape judgment was to discriminate which side of the pattern had a missing dot, and the movement judgment was to discriminate the direction in which the pattern rotated. The discriminability of these two judgments was equated by adjusting the contrast of the pattern. The partial-report procedure was implemented using an auditory cue specifying a particular item from a set of six. The results showed cue-delay effects for both shape and movement. Similarly, cue-delay effects for naming color patches were shown in another study (van der Heijden, 1984). In contrast, no cue-delay effect was found for comparing line length within a display (Schulz, 1980), little effect was found for reporting the direction of linear movement (Demkiw \& Michaels, 1976), and no consistent effect was found for recognizing nonsense forms (Schulz, 1982; Steffy \& Eriksen, 1965).

Some (e.g., Haber, 1983) have criticized the studies that have shown a cue-delay effect for noncharacter stimuli. For example, in Treisman et al. (1975), the subjects were screened to include only those showing a partial-report advantage over full report; 5 of 17 subjects were excluded on that basis. As a result, Haber questioned the relevance of the result to the population as a whole. Another concern raised in the Treisman et al. study is that the effect of cue delay interacted with other characteristics of the displays, such as spatial position, expectations about partial versus total report, and the homogeneity of the stimuli. These dependencies indicate that the cue-delay effect may not be the same for all stimuli.

The generality of the cue-delay effect may also be limited by other factors. For instance, the cue-delay effect may be specific to stimuli belonging to discrete categories rather than to stimuli belonging to a perceptual continuum. As it happens, all of the noncharacter studies (except that of Schulz, 1980) employed only a few distinctive stimulus values (for example, two opposite directions of movement, or four colors). Such stimuli can be represented by discrete categories.

The only study using continuously varying stimuli was that of Schulz (1980). In this study, the stimulus contained several rows of two horizontal lines and was followed by a tone indicating which row was to be judged. The subjects were required to judge whether the lines in the indicated row were the same length. A signal detection analysis was used to estimate the sensitivity to line length as a function of cue delay. In two experiments, no reliable difference was found between cue delays of $0 \mathrm{msec}$ and $1,000 \mathrm{msec}$. Schulz argued from these results that the cuedelay effect was a result limited to certain kinds of stimuli, such as letters.

The present study pursued the generality of cue-delay effects. As in Schulz's (1980) study, stimuli were used that varied in small steps approximating a continuum. However, there were several differences between this study and Schulz's experiment. First, the judgment was made to be more analogous to traditional partial-report experiments in that a comparison within the display was not required. Second, cues were presented both before and after the display to provide further opportunity for a cue-delay effect (see Eriksen \& Collins, 1969). Third, the entire psychometric function was measured and the results summarized by the difference threshold for a given performance level. The last modification avoided floor and ceiling effects, avoided inducing different strategies for particularly easy or hard conditions, and provided a measure of the size of the cue-delay effect in terms of the stimulus.

\section{The Task}

The experiments applied psychophysical methods to the partial-report paradigm. In the prototype experiment, a length discrimination is required for one of several lines in a multiple-line display (Palmer, 1988). Figure 1 depicts a typical display sequence. The sequence of visual stimuli in a trial begins with an initial fixation display, followed by a study stimulus, followed by a test stimulus. Between displays are intervals in which no stimulus is visible within the circular aperture. The study stimulus consists of four lines arranged around a fixation point, and the test stimulus consists of a single line at one of the same positions. The observer's task is to judge whether the test line is longer or shorter than the study line in the

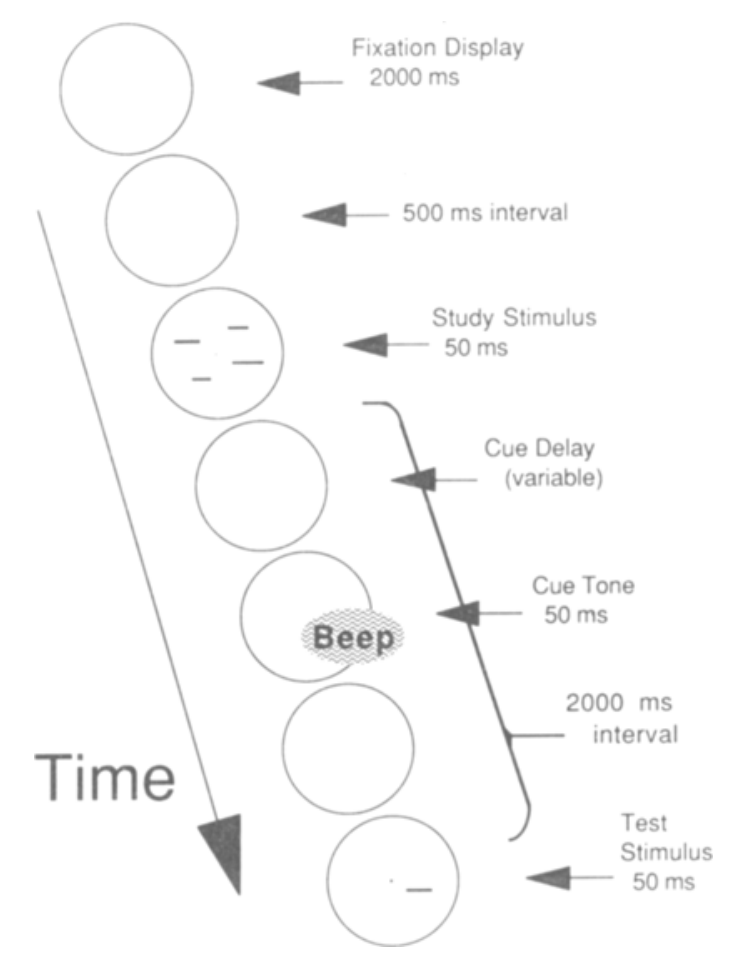

Figure 1. A schematic illustration of the display sequence. A fixation display is followed by a study stimulus, followed by a test stimulus, separated by intervals in which no stimulus is visible. Durations and intervals between the displays are given on the right. In this example, an auditory postcue of low frequency was presented to the right ear to indicate which line was to be tested. For precues, the cue was presented before the study stimulus. 
same position. This is a memory task, because something about the study display must be remembered during the 2 -sec interval until the test display is presented.

An auditory cue is used to indicate which of the four study lines will be tested. The cue indicates a particular stimulus position by frequency and by ear. For example, a high tone to the left ear indicates a stimulus in the upper left of the display. The cue is a $100 \%$ valid indicator of the to-be-tested position. The cue simplifies the task for the observer: If there is a memory available at the time of cue that is not available $2 \mathrm{sec}$ later, the observer can make use of the cue to attend to a particular line. Then, instead of having to remember four lines, the observer need remember only a single line. This cued discrimination task is analogous to partial report, in which the cue indicates what stimuli must be remembered for later report.

\section{GENERAL METHOD}

\section{Observers}

Seven observers were employed across the set of experiments. All were adults from 20 to 40 years of age, all had normal or corrected-to-normal vision, and all were paid $\$ 5$ per hour (except Observer 1 , the author). The observers and their identifying numbers were those used in a related study of attention (Palmer, 1988).

\section{Apparatus}

The displays were controlled by a Hewlett-Packard computer (Model 9817) and were presented on a 14-in. cathode ray tube (Hewlett-Packard Model 35122A), which has a greenish, fast-decay P31 phosphor, a $60-\mathrm{Hz}$ raster refresh, and a resolution of $512 \times$ 390 pixels. The displays were viewed from a distance of $78 \mathrm{~cm}$ through a $13-\mathrm{cm}$ aperture-reduction screen located $20 \mathrm{~cm}$ in front of the display. This combination resulted in a viewing area of $12^{\circ}$ in diameter. All displays were black-on-white (i.e., reverse video), thus avoiding possible phosphor persistence following stimulus offsets. The cathode ray tube was lit to an intensity equivalent to a luminance of $170 \mathrm{~cd} / \mathrm{m}^{2}$. ${ }^{1}$ The surrounding reduction screen was a similar light green of matched luminance. The displayed lines had a luminance of $70 \mathrm{~cd} / \mathrm{m}^{2}$, yielding a contrast of $1: 2.5$.

\section{Stimuli}

Stimuli in the initial experiments were horizontal lines that were varied from a standard length of $60 \mathrm{~min}$ arc. As shown in Figure 1, four lines were arranged on an imaginary circle $3^{\circ}$ from a central fixation point. The centers of the lines were always placed on the circle at orientations of $1,4,7$, and 10 o'clock.

The stimulus sequence is illustrated in Figure 1. There were three successive displays, with intervals between displays. The fixation point was presented for $2,000 \mathrm{msec}$, the study stimulus for $50 \mathrm{msec}$, and the test stimulus for $50 \mathrm{msec}$. The fixation display was removed $500 \mathrm{msec}$ before the study display and the study display was removed 2,000 msec before the test display.

Auditory cues were presented once, either before or after the study display. Timing relative to the study stimulus is specified by cue delay, which is the interval between study stimulus offset and cue onset. Cues after the stimulus offset have positive cue-delay values and are called postcues; cues before the stimulus offset have negative values are are called precues. A postcue delay is the interval between the stimulus and the cue. For example, a cue delay of $100 \mathrm{msec}$ means that the offset of the stimulus was followed $100 \mathrm{msec}$ later by the onset of the cue tone. A precue delay is the interval between cue onset and stimulus offset, which includes the duration of the cue and the stimulus. For example, a cue delay of -100 msec means that the 50 -msec cue tone was followed immediately by the 50 -msec stimulus. Thus, the -100 -msec cue-delay condition is a successive presentation of cue and stimulus. The cues were presented to either the right or the left ear at either 500 or $3000 \mathrm{~Hz}$. They had a duration of $50 \mathrm{msec}$ and were matched in loudness. Position was indicated by a combination of ear and frequency. The ear to which the tone was presented indicated horizontal position, and the frequency of the tone indicated vertical position. For example, the upper left position was cued by a high-frequency tone to the left ear.

In the test display, the length of the standard line was always $60 \mathrm{~min}$ arc. In the study display, there were four lines. Three lines were distractors and one line was the comparison stimulus. The length of the comparison line was selected from a range of plus or minus approximately two times the estimated difference threshold. For example, if the difference threshold was estimated to be $6 \mathrm{~min}$ arc for a 60-min-arc standard, then comparison lines were between 48 and $72 \mathrm{~min}$ arc. The length of each distractor line was chosen from the same 48- to 72-min-arc interval. In summary, the discrimination was between a 60 -min-arc standard in the test display and a variable comparison in the study display.

\section{Procedure}

Observers were instructed to make a two-alternative forced-choice discrimination of line length. Following the test display, they pressed one key if they thought the test line was shorter than the corresponding study line and another key if they thought the test line was longer. There was no time pressure, and response accuracy feedback was provided by tones. An adaptive procedure (the 3:1 rule; Levitt, 1971) was used to select study stimuli from the four to eight lengths that were near the difference threshold. The psychometric function was formed as the proportion of "longer" responses as a function of the change in length. The function was fit to a cumulative normal by probit analysis (Finney, 1971), and the difference threshold was defined as half of the difference between the length that produced the response "longer" $25 \%$ of the time and the length that produced "longer" $75 \%$ of the time.

Both between- and within-subjects analyses are presented. For between-subjects analyses, the difference thresholds were determined for each observer and statistics were calculated from the sample of observers; for the within-subjects analyses, the difference thresholds were determined for individual blocks of an observer and statistics were calculated from the sample of blocks for an individual observer. Trials were presented in blocks of 32 or 48 trials, and a session consisted of 8 to 10 blocks. One session was conducted per day. Each observer participated in at least 11 practice sessions in size discrimination before any data for this study were collected. In addition, before each experiment, observers participated in 1 or more specific practice sessions for that experiment. This resulted in at least 3,800 practice trials per observer.

\section{EXPERIMENT 1}

The first experiment measured the cue-delay effect for line length. Length-difference thresholds were estimated at cue delays ranging from -500 to $500 \mathrm{msec}$. The use of negative cue delays (precues) followed that of Eriksen and Collins (1969), who argued that the perception of the cue takes time and thus a precue of perhaps $150 \mathrm{msec}$ may effectively be simultaneous with the stimulus. Eriksen and Collins supported this possibility by showing that partial report of letters improves as cues are presented up to $150 \mathrm{msec}$ before stimulus offset. 


\section{Method}

Cue delays of $-500,-120,120$, and $500 \mathrm{msec}$ were presented in a mixed list design. Equal numbers of precues and postcues were used to encourage observers to pay attention to the cues. Seven observers participated in four sessions with four cue-delay conditions, yielding 256 trials per condition per observer.

\section{Results}

Logarithms of length-difference thresholds are plotted in Figure 2 as a function of cue delay for each observer. ${ }^{2}$ The mean difference threshold increased from $0.54 \pm 0.03$ $\log$ min arc at cue delay -500 msec to $0.83 \pm 0.05 \log$ $\mathrm{min}$ arc at cue delay $500 \mathrm{msec}$. This is a reliable difference of $0.29 \pm 0.04 \log \min \operatorname{arc}[t(6)=7, p<.001]$. In other words, the difference thresholds nearly doubled from the earliest precue to the latest postcue. Furthermore, this difference in the thresholds was reliable for all $7 \mathrm{ob}-$ servers [e.g., for Observer $1, t(7)=6, p<.001]^{3}$ Thus, the cue-delay effect is general to line-length discrimination in the entire sample of observers.

The use of precues raises the possibility of eye movement, despite instructions to maintain fixation. To check for this, 4 of the observers were examined after the experiment for eye movement under the conditions of the experiment. A judge watched the observers' eyes. In an initial test, the judge was able to detect $94 \%$ of intentional $3^{\circ}$ saccades to the line stimuli (based on 32 trials). Next, the judge watched the observers under the conditions of Experiment 1 (in each case for 32 trials). Observers varied considerably in their judged ability to maintain fixation.

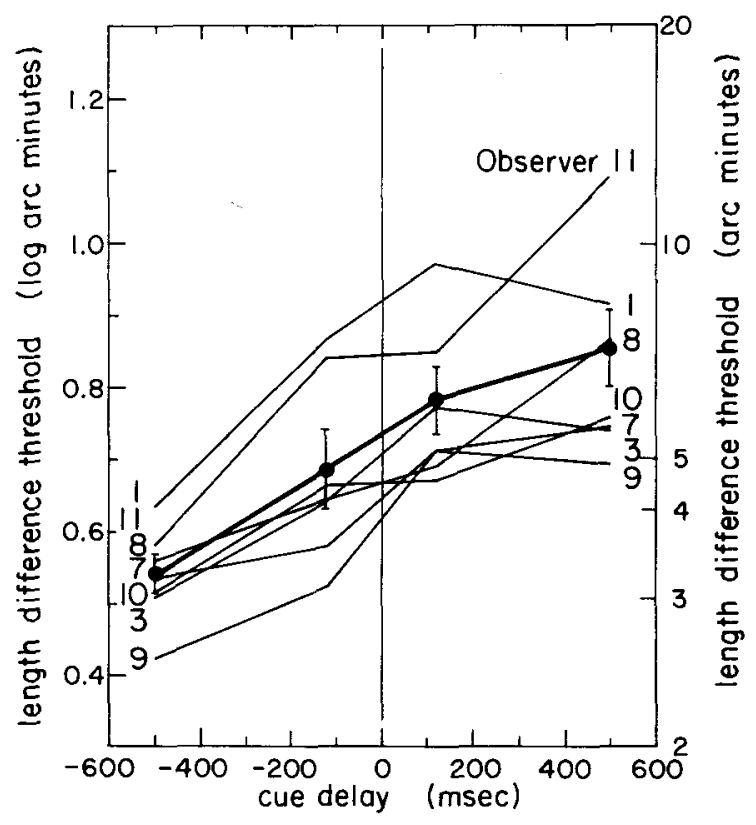

Figure 2. Length-difference thresholds in log min arc are shown as a function of cue delay (Experiment 1). The bold curve is the mean difference threshold pooling across observers and the light curves are individual difference thresholds identified by the observer's number. Logarithmic difference threshold values are shown on the left side and linear values are shown on the right side.
Observer 7 never made detectable saccades, whereas $\mathrm{Ob}$ server 3 made detectable saccades on $89 \%$ of the trials. Observers 1 and 11 made saccades on $61 \%$ and $25 \%$ of their trials, respectively. Because of these saccades, the low difference thresholds in the -500 -msec condition may be due to foveation of the stimulus. For this reason, it may be more appropriate to compare the -120 - and 500msec cue delays to avoid possible effects of eye movement. The thresholds for these two conditions differed by $0.15 \pm 0.03 \log \min$ arc $[t(6)=5, p<.001]$ and were reliable for 4 of the 7 observers. Thus, even when the earliest cue-delay condition is excluded because of possible eye movement, a cue-delay effect remains.

\section{Discussion}

All 7 observers showed an increase in difference threshold as the cue delay was increased. The size of the effect can be conservatively measured by comparing $-120-\mathrm{msec}$ and 500 -msec conditions to yield a $40 \%$ increase in the mean difference threshold. Thus, the cuedelay effect is found consistently for line-length discrimination.

The -500 -msec cue delay showed a substantial further improvement in the difference threshold compared with the -120 -msec cue delay. Such a dramatic improvement for early precues was not found for the partial report of characters (Eriksen \& Collins, 1969). This large precue advantage may be due to eye movement or to an advantage of an early shift in attention. Perhaps it would also be found with characters if ceiling performance was avoided. These issues will be taken up in Experiment 3; but first, the generality of Experiment 1 will be extended further.

\section{EXPERIMENT 2}

In Experiment 2, the cue-delay effect was measured for shape discrimination of outlined rectangles. Demonstrating that shape judgments show cue-delay effects similar to that found for the size judgment of Experiment 1 would help to further establish the generality of these effects for different kinds of stimuli.

\section{Method}

The stimuli were outlined rectangles varying around a standard of $40 \mathrm{~min}$ arc height $\times 80 \mathrm{~min}$ arc width. To obtain shape-difference thresholds, the shape was elongated by changing the width and height by equal but opposite amounts, thus maintaining a constant perimeter. Figure 3 shows a sample study display containing four rectangles and a test display containing a single rectangle. In the study display, the elongation of the rectangles was varied; in the test display, the single rectangle was always the standard elongation. Observers judged the direction of elongation change from study to test. For example, Figure 3 shows a test rectangle that is more elongated than the corresponding study rectangle. Difference thresholds were calculated in terms of min arc of elongation. For example, a 2-min-arc elongation-difference threshold denotes that comparison stimuli of either $38 \times 82$ or $42 \times 78$ were discriminable on $75 \%$ of the trials from the standard of $40 \times 80 \mathrm{~min}$ arc. Otherwise, the method was identical to that of Experiment 1. Two ob- 
servers participated in four sessions with four cue-delay conditions, for a total of 256 trials per condition per observer.

\section{Results}

Shape-difference thresholds are shown in Figure 4 as a function of cue delay for 2 observers. The difference thresholds are logarithmically scaled in units of min arc of elongation. As in Experiment 1, the difference thresholds increased with cue delay. The difference between the thresholds for the most extreme cue delays was $0.31 \pm 0.05 \mathrm{log} \min$ arc for Observer $3[t(7)=6, p<$ $.001]$ and $0.34 \pm 0.08 \mathrm{log} \mathrm{min}$ arc for Observer 7 [ $t(7)$ $=4, p<.005]$. Exclusion of the $-500-\mathrm{msec}$ cue delay because of possible eye movement leaves a difference between the $-120-\mathrm{msec}$ and $500-\mathrm{msec}$ conditions of $0.26 \pm 0.05 \log \min$ arc for Observer $3[t(7)=5, p<$ $.001]$ and $0.20 \pm 0.04 \mathrm{log}$ min arc for Observer $7[t(7)$ $=5, p<.001]$. Thus, the cue-delay effect found in Experiment 1 generalizes to a shape-discrimination task.

\section{EXPERIMENT 3}

The interpretation of any partial-report experiment, such as those discussed here, depends on how the cue acts. The simple assumption is that the cue is only an indicator of the stimulus that is to be remembered. But does the cue have other effects as well? Or, to question the assump-
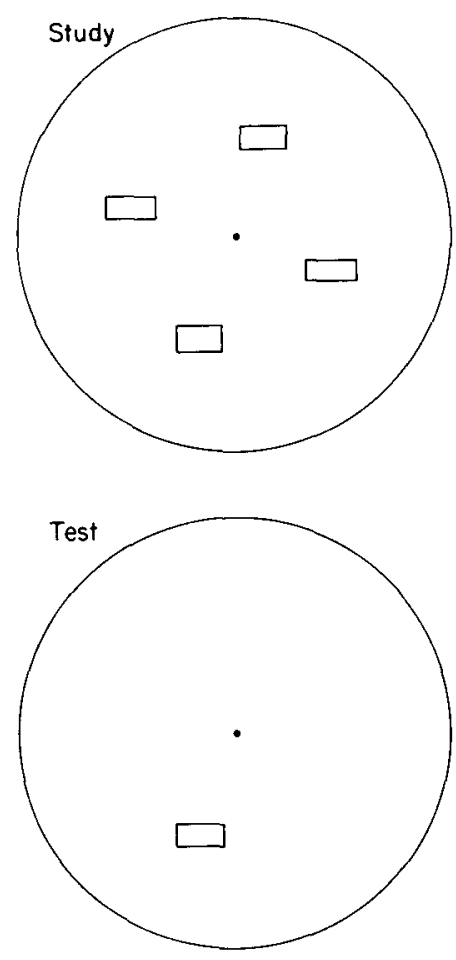

Figure 3. A scale drawing illustrating study and test displays of rectangles as used in Experiment 2.

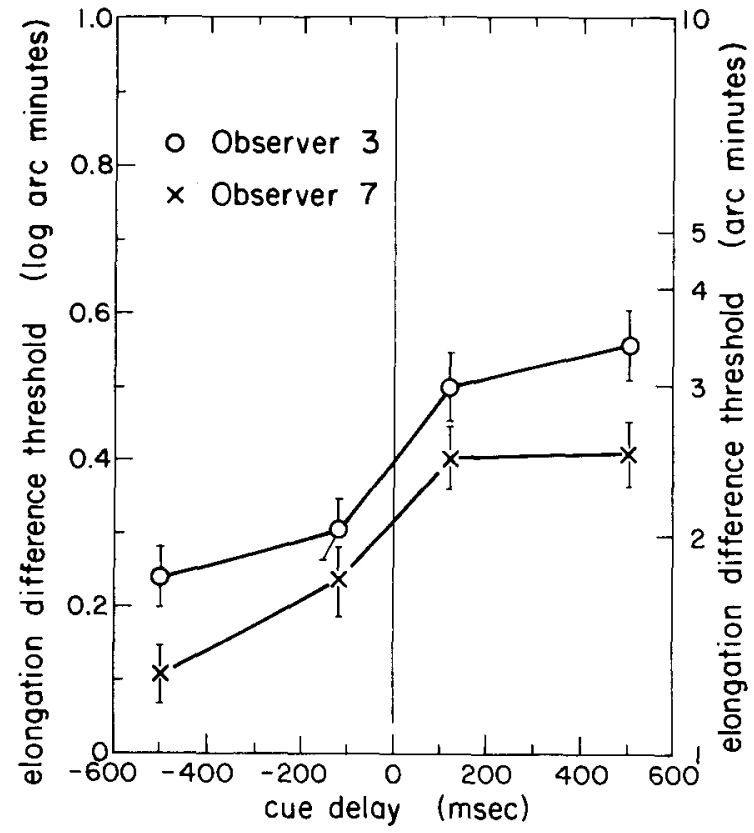

Figure 4. Elongation-difference thresholds are shown as a function of cue delay for 2 observers (Experiment 2). Elongation is expressed as the log min arc change for the equal magnitudes of height decrement and width increment. Linear values are shown at the right.

tion in a different way, is the cue effective in its purpose of indicating a particular stimulus? One control is to compare the late-postcue conditions to full report (Sperling, 1960). This late-postcue control addresses the question of whether a late postcue is equivalent to the absence of a cue. Equivalence is predicted if the cue's advantage depends on a memory that is exhausted by the time the late postcue is presented. On the other hand, if the cue also interrupts processing by distracting attention or by changing strategies, then the late-postcue condition might differ from a no-cue condition.

In a second control, a related question is addressed for precues. If a cue is completely successful in indicating a stimulus to be remembered, then a sufficiently early cue should be equivalent to a single-stimulus display. In other words, an early-precue control tests whether the cue makes a multiple-stimulus display equivalent to a singlestimulus display. Alternatively, an early precue might be a more powerful indicator than a single stimulus. For example, an early precue might allow an eye movement or an attention shift that would not be possible with an uncued single stimulus of brief duration. If so, the earlyprecue condition should show better performance than the single-stimulus condition. This was a particular concern in the present experiments, in which the $-500-\mathrm{msec}$ precue allowed plenty of time for a possible eye movement toward the cued stimulus. Moreover, some observers 
did appear to make eye movements. If these eye movements were effective in improving performance, then the early-precue condition should have had a lower difference threshold than a single-stimulus condition.

\section{Method}

Experiment 3 included both the late-postcue and the early-precue controls. The experiment consisted of two cue conditions and two set-size conditions. Cue conditions were identical to those of Experiment 1 , except that the cue delays were limited to -500 and $500 \mathrm{msec}$. Set-size conditions differed in that there were no audio cues; instead, there was a study set size of either one or four lines. Otherwise, the stimuli and the procedures were identical to those of Experiment 1. Four observers participated in four sessions with four conditions, yielding 256 trials per condition per observer.

\section{Results}

Table 1 contains the resulting difference thresholds for the 4 observers, with their means at the bottom. The second and third columns are length-difference thresholds for the cue conditions similar to those of Experiment 1. The fourth and fifth columns are difference thresholds for the set-size conditions. Several points can be made. First, consider the main effects. The cue conditions replicated Experiment 1 by showing a difference between thresholds of $0.31 \pm 0.05 \log \mathrm{min}$ arc; the set-size conditions replicated another study (Palmer, 1988) by showing a difference between thresholds of $0.35 \pm 0.08 \mathrm{log} \mathrm{min}$ arc. Second, consider the early-precue control that compared the -500 -msec cue-delay condition with the set-size-one condition. The mean difference between thresholds for these conditions was $-0.04 \pm 0.06 \log \mathrm{min}$ arc, which is not reliable $[t(3)=0.6, p>.1]$. A closer look, however, shows that this difference was reliable for Observer 3 , who showed a 0.19-log-min-arc advantage for the precue condition $[t(7)=7, p<.001]$. This is the same observer who was judged to have made consistent eye movements in Experiment 1. Thus, for Observer 3, the potential artifact of an advantage for precues over a single stimulus was found. On the other hand, the other 3 observers showed similar thresholds for the precue and singlestimulus conditions, indicating an absence of eye movement or of attentional artifacts. Third, consider the latepostcue control that compared a 500 -msec cue-delay condition with a set-size-four condition. The mean difference

Table 1

Length-Difference Thresholds for the Early-Precue and Late-Postcue Controls in Experiment 3

\begin{tabular}{|c|c|c|c|c|}
\hline \multirow[b]{2}{*}{ Observer } & \multicolumn{2}{|c|}{$\begin{array}{l}\text { Cue Conditions } \\
\text { (set size = four) }\end{array}$} & \multicolumn{2}{|c|}{$\begin{array}{l}\text { Set Size Conditions } \\
\text { (no cue) }\end{array}$} \\
\hline & -500 & 500 & one & four \\
\hline 1 & $0.73 \pm 0.04$ & $1.10 \pm 0.07$ & $0.64 \pm 0.05$ & $1.12 \pm 0.07$ \\
\hline 3 & $0.41 \pm 0.04$ & $0.80 \pm 0.05$ & $0.60 \pm 0.04$ & $0.91 \pm 0.06$ \\
\hline 7 & $0.58 \pm 0.04$ & $0.76 \pm 0.05$ & $0.61 \pm 0.04$ & $0.73 \pm 0.04$ \\
\hline 11 & $0.59 \pm 0.04$ & $0.90 \pm 0.05$ & $0.61 \pm 0.04$ & $1.08 \pm 0.07$ \\
\hline Mean & $0.58 \pm 0.06$ & $0.89 \pm 0.08$ & $0.61 \pm 0.01$ & $0.96 \pm 0.09$ \\
\hline
\end{tabular}

Note-Values are length-difference thresholds in log min arc. For the early-precue control, compare the -500 -msec cue-delay condition with the set-size-one condition. For the late-postcue control, compare the 500msec cue-delay condition with the set-size-four condition. between thresholds was not reliable $[0.07 \pm 0.05 \log \mathrm{min}$ arc, $t(3)=1, p>.1]$. However, this difference was reliable for 2 of the 4 observers ( 3 and 11). Thus, a 500-msec postcue is not always the same as no cue.

\section{Discussion}

Consider first the early-precue control. A 500-msec precue produced the same difference threshold as a singlestimulus condition in 3 of the 4 observers. Interpreted in terms of attention, the cue allowed a change in attention that was as effective as an absence of distractors. This confirms the effectiveness of the cue as assumed in the usual interpretation of cue-delay effects. If the cue were any less effective than a single stimulus, the cue-delay effect would be attenuated. In Experiment 1, such an attenuation would be evident if a 0 -msec cue-delay condition were compared with a single-stimulus condition. Only when precues are used is the cue as effective as a single stimulus.

These results are relevant to the spurious improvement of performance caused by eye-movement or attentional effects in the presence of a precue. Such spurious effects will result in improved performance with precues compared with single stimuli. After all, there is no way to shift attention to the uncued single stimulus before it is displayed. The artifact was found for 1 observer. Certainly, improved procedures are needed to prevent such differences in individual strategy. On the other hand, it is promising that 3 observers did not show an advantage for the precue condition.

Consider next the late-postcue control. A 500-msec postcue condition and an uncued condition both elevated difference thresholds, compared with a precue condition, by about $0.3 \log$ units. However, a late postcue was not equivalent to the absence of a cue for all observers. Perhaps a longer cue delay is necessary for this equivalence (see Laming \& Scheiwiller, 1985). In particular, the late postcue may still reduce the memory load relative to the no-cue control for the interval between the cue and the test. Alternatively, this effect may be an artifact of a change in fixation. That is, some observers might have used the late cue to foveate the test stimulus despite instruction to the contrary. Given these possibilities, the conservative conclusion is to recognize only a general similarity between the use of cues and the variation of set size.

\section{GENERAL DISCUSSION}

The cue-delay effect was found in three experiments measuring size and shape discrimination. This finding extends the results of Treisman et al. (1975) and others. Together, these results demonstrate that the cue-delay effect is not specific to character stimuli. Before considering interpretations of the cue-delay effect, I will relate the present results to those of previous studies.

One reason the cue-delay effect was found in these experiments and not in others is that precues were used here. Consider Schulz's (1980) study. Although similar to the present study, it restricted the cue delays to a range of 0 - 
$1,000 \mathrm{msec}$. Since there was little if any effect of such postcues in the present study, data from Schulz's study and the present study are not in conflict.

The present study also differed from previous studies with respect to observer strategy and degree of practice. The partial-report procedure requires the observer to follow a relatively complicated strategy of using a cue to improve performance. Unfortunately, an observer can choose not to use the cue (see Chow, 1985; Sperling, 1960). For this reason, it is important to have explicit instructions and extensive practice. It is not obvious that the previous studies trying to generalize partial report were successful in this regard. In particular, observers in these studies had relatively limited practice: Demkiw and Michael's (1976) cue-delay study included only 96 trials per observer; Schulz (1980) included at most 720 partialreport trials per observer; Treisman et al. (1975) included more trials, but only 720 trials were run before they excluded some of their observers. In contrast, the present Experiment 1 included at least 3,800 practice trials before an experiment of 1,024 trials.

A related factor is the usefulness of the cue to the observers. In the current experiments, half the cues were precues; in previous studies, all the cues were either simultaneous or postcues. It is perhaps noteworthy that Observer 3 in Experiment 1 reported ignoring the cue after an initial session. Only after further instruction did this observer follow the intent of the experiment and pay any attention to the cue. In summary, previous experiments may not have found a robust cue-delay effect because of inadequate instruction and training of observers.

\section{Interpreting the Cue-Delay Effect}

What causes the cue-delay effect? This question is complicated in the present study because much of the effect was for precues. In other words, negative cue delays have at least as large an effect as positive cue delays (cf. Eriksen \& Collins, 1969). The following discussion first considers two hypotheses specific to precues, and then turns to more general hypotheses about the origin of cue-delay effects.

Attention effects during the stimulus display. With a postcue, one can be fairly certain that the effect of cue delay depends on memory of some sort, because the stimulus is no longer present. In contrast, precues may change the processing of the stimulus display, rather than the processing of a memory. For example, observers might shift their gaze or attention to the cued stimulus. Indeed, with the -500 -msec precue, some observers were judged to make an eye movement. It is not known whether this movement was fast enough to be complete before the stimulus was removed, but it might have been. On the other hand, a -120-msec cue delay leaves little time for either an eye movment or an attention shift before stimulus offset. If such shifts are completed after stimulus offset, they can affect only memory.

The possibility of an attention effect before stimulus offset was addressed by the precue control of Experiment 3.
The idea was to compare a precue condition with an uncued single-stimulus condition. If the precue had engendered an attention shift, then the precue condition should have shown better performance than the single-stimulus condition. Such a difference was not reliably found. The -500 -msec cue-delay condition had about the same difference threshold as the single-stimulus control for 3 of the 4 observers. Nevertheless, further evidence is needed before a memory interpretation of precues is convincing.

The cue processing hypothesis. Why is there a precue effect if it is not an attention shift before stimulus offset? One possibility is that it takes time to process the cue. That is, a memory loss occurs while attention switches to the cued stimulus (see Sperling \& Reeves, 1980). Suppose that a cue is presented simultaneously with the study stimulus. Processing starts on both the cue and the study stimulus and after some critical time $(X)$, the cue is recognized as an indication that one part of the study stimulus is relevant to the memory task. Only at this time does preferential processing begin for the cued part of the study stimulus. It seems likely that by time $X$ the memory for the relevant stimulus has already been degraded. Thus, the processing requirements for the cue cause the cue delay to be an underestimate of the relevant retention interval by an amount $X$. In other words, the cue delay function should be shifted to the right by adding $X$ to each delay value. A 0 -msec cue delay is functionally a retention interval of $X \mathrm{msec}$ and a $-X-\mathrm{msec}$ cue delay is a 0 -msec retention interval.

This hypothesis abandons a common interpretation of cue delay. Assume that there is a very short-term memory from which information is recoded into a more durable memory. Assume further that in partial-report tasks, the cue is used to guide what information is recoded. Consequently, the cue delay affects the retention time in the very short-term store, and cue delay is interpreted as an indirect manipulation of the retention interval. Such an interpretation cannot be maintained with the cue-processing hypothesis. Cue delay has to be corrected by adding some time for the processing of the cue. Furthermore, the hypothesis of a single and constant processing time must be changed to the more general hypothesis of a distribution of processing times. This further weakens any interpretation of cue delay as being analogous to a retentioninterval manipulation. In summary, the assumption that the cue takes time to process can easily account for the effect of precues; however, such an account complicates the interpretation of cue delay.

Alternative memory hypotheses. The cue-delay effect may be explained by several alternative memory hypotheses. There may be a large-capacity precategorical store that decays quickly (Sperling, 1960), there may be associations formed between physical attributes and categorical information that are forgotten quickly (e.g., Coltheart, 1980), or there may be ongoing perceptual processes that can be modified by the cue before they are completed (Haber, 1983; Schulz, 1980). The present results restrict the form of these hypotheses but do not dis- 
tinguish among them. For example, by the association hypothesis, information about object identifications (categorical information) as well as visual attributes is established while a display is present. However, before this information can be integrated into other more durable representations, forgetting begins to occur for associations that relate categorical information to spatial position and other visual attributes. This hypothesis is usually developed to account for the forgetting of categorical information. The present results suggest that associations need to be lost between visual attributes as well as between categorical and visual information. In summary, the presence of a cue-delay effect for noncharacter stimuli restricts but does not distinguish among the alternative hypotheses for very short-term visual memory.

\section{Related Questions}

Three unresolved questions deserve mention. First, are there any special consequences of making the test stimulus always the standard, as was done in the current experiments? The issue arises because some observers reported using a strategy in which they categorized each study stimulus as being larger or smaller than a memorized standard. Such a strategy may reduce the memory load by allowing an observer to remember only the categorization rather than the stimulus value (e.g., line length). If this does occur, the present experiments may have underestimated the effects of cue delay for a pure memory of the stimulus value. Second, is there a difference between the cue-delay effect for characters and that for noncharacter stimuli? It may be, for example, that visual attributes have no postcue effect as claimed by Schulz (1980). I think the answer to this question will require better studies of both character and noncharacter stimuli. In particular, character stimuli must be investigated in a fashion that avoids ceiling and floor effects, which may obscure large effects of precues with character stimuli. Third, is the cued discrimination paradigm a measure of informational persistence, or visible persistence (Coltheart, 1980)? Although the paradigm is modeled after partial report, it also requires a visual judgment similar to that required in integration paradigms (Di Lollo, 1980; Eriksen \& Collins, 1967). To settle this issue, more data are needed on the cued discrimination paradigm and a clearer theoretical distinction needs to be made among different kinds of persistence.

In summary, a cue-delay effect was shown for the discrimination of size and shape information. This supports and extends the work of Treisman et al. (1975), which showed that cue-delay effects in partial report can be found for visual attributes. To account for these results, any hypothesis must allow for memories of visual attributes as well as for categorical information.

\section{REFERENCES}

Averbach, E., \& Coriell, A. S. (1961). Short-term memory in vision. Bell System Technical Journal, 40, 309-328.
Chow, S. L. (1985). Iconic store and partial report. Memory \& Cognition, 13, 256-264.

CHow, S. L. (1986). Iconic memory, location information, and partial report. Journal of Experimental Psychology: Human Perception \& Performance, 12, 455-465.

Coltheart, M. (1980). Iconic memory and visible persistence. Perception \& Psychophysics, 27, 183-228.

DemKIW, P., \& Michaels, C. F. (1976). Motion information in iconic memory. Acta Psychologica, 40, 257-264.

DEN HEYER, K. (1972). The processing of multidimensional information from iconic storage: Perceptual independence and comparative rates of decay. Acta Psychologica, 36, 431-442.

Di Lollo, V. (1980). Temporal integration in visual memory. Journal of Experimental Psychology: General, 109, 75-97.

Dick, A. O. (1969). Relations between the sensory register and shortterm storage in tachistoscopic recognition. Joumal of Experimental Psychology, 82, 279-284.

Duncan, J. (1983). Perceptual selection based on alphanumeric class: Evidence from partial reports. Perception \& Psychophysics, 33, 533-547.

ERIKSEN, C. W., \& Collins, J. F. (1967). Some temporal characteristics of visual pattern perception. Journal of Experimental Psychology, 74, 476-484.

ERIKSEn, C. W., \& Collins, J. F. (1969). Temporal course of selective attention. Journal of Experimental Psychology, 80, 254-261.

FARRELL, J. E. (1984). Visible persistence of moving objects. Journal of Experimental Psychology: Human Perception \& Performance, 10 , 502-511.

Finney, D. J. (1971). Probit analysis (3rd ed.). Cambridge, England: Cambridge University Press.

HaBER, R. H. (1983). The impending demise of the icon: A critique of the concept of iconic storage in visual information processing. $B e$ havioral \& Brain Sciences, 6, 1-54.

IRWIN, D. E. , Yeomans, J. M. (1986). Sensory registration and informational persistence. Journal of Experimental Psychology: Human Perception \& Performance, 12, 343-360.

LAMING, D., \& SCHeIWILleR, P. (1985). Retention in perceptual memory: A review of models and data. Perception \& Psychophysics, 37, $189-197$.

LEviTT, H. (1971). Transformed up-down methods in psychoacoustics. Journal of the Acoustical Society, 49, 467-477.

MeriKLe, P. M. (1980). Selection from visual persistence by perceptual groups and category membership. Journal of Experimental Psychology: General, 109, 279-295.

Mewhort, D. J. K., Campbell, A. J., Marchetti, F. M., \& CampBELL, J. I. D. (1981). Identification, localization, and "iconic memory": An evaluation of the bar-probe task. Memory \& Cognition, 9, 50-57.

Meyer, G. E., Maguire, W. M. (1977). Spatial frequency and the mediation of short-term visual storage. Science, 198, 524-525.

PALmer, J. (1988). Attention and the visual information remembered from a brief presentation. Manuscript submitted for publication.

PHILlIPS, W. A. (1974). On the distinction between sensory storage and short-term visual memory. Perception \& Psychophysics, 16, 283-290.

RumelharT, D. E. (1970). A multicomponent theory of the perception of briefly exposed visual displays. Journal of Mathematical Psychology, 7, 191-218.

SchUlz, T, (1980). Iconic memory-An artifact of perceptual reconstruction processes? Psychological Research, 42, 275-294.

SCHULZ, T. (1982). Ikonisches Gedächtnis für visuelle Elementarmerkmalen: Vom schlecht zugänglichen visuellen Speicher und dem langandauernden Ikon [Iconic memory for simple visual features: On the inaccessible visual store and the long-lasting icon]. Archiv für Psychologie, 134, 1-31.

SPERLING, G. (1960). The information available in brief visual presentations. Psychological Monographs: General \& Applied, 74, 1-29.

SPERLING, G. (1969). A model for visual memory tasks. In R. N. Haber (Ed.), Information processing approaches to visual perception (pp. 1831). New York: Holt, Rinehart \& Winston. 
SPERLING, G., ReEves, A. (1980). Measuring the reaction time of a shift of visual attention. In R. S. Nickerson (Ed.), Attention and performance VIII (pp. 347-360). Hillsdale, NJ: Erlbaum.

STEFFY, R. A., ERIKSEN, C. W. (1965). Shonterm, perceptualrecognition memory for tachistoscopically presented nonsense forms. Journal of Experimental Psychology, 70, 277-283.

TownSEND, V. M. (1973). Loss of spatial and identity information following a tachistoscopic exposure. Journal of Experimental Psychol. ogy, 98, 113-118.

Treisman, A., Russell, R., Green, J. (1975). Brief visual storage of shape and movement. In P. M. A. Rabbitt \& S. Dornic (Eds.), Attention and performance $V$ (pp. 699-721). New York: Academic Press.

Turvey, M. T., \& Kravetz, S. (1970). Retrieval from iconic memory with shape as the selection criterion. Perception \& Psychophysics, $8,171-172$.
VAN der Heijden, A. H. C. (1984). Postcategorical filtering in a barprobe task. Memory \& Cognition, 12, 446-457.

VON WRIGHT, J. M. (1968). Selection in visual memory. Quarterly Journal of Experimental Psychology, 20, 62-68.

\section{NOTES}

1. The tube was luminous due to the reverse video and was illuminated by indirect lighting.

2. Logarithmically scaled thresholds have the advantage of roughly constant variability; they are used in all figures and statistics.

3 . Individual $t$ tests were based on eight blocks of data, two independent blocks for each of four sessions.

(Manuscript received March 23, 1987; revision accepted for publication August 18, 1987.)

\title{
Announcement
}

\author{
A Marcus Wallenberg Symposium on \\ Structure and Perception of Electroacoustic Sound and Music \\ Lund, Sweden \\ August 21 -28, 1988
}

An international symposium on Structure and Perception of Electroacoustic Sound and Music will be held August $21-28,1988$, under the auspices of the Marcus Wallenberg Foundation, the Province of Malmöhus, the Royal Swedish Academy of Music, the Swedish National Institute for Concerts, the Society of Swedish Composers, and Lund University. Organizers are the Departments of Musicology, Neurophysiology, and Psychiatry at Lund University.

The symposium will consist of three coordinated parts: A Master Class for composers, starting on August 21 ; a Scientific Session for musicologists, neurophysiologists, and psychologists, in which scientific lectures and discussions on structure and perception of electroacoustic sound and music are scheduled; and a 6-day electroacoustic Music Festival.

Twenty-five composers will participate in the Master Class. Morton Subotnick, U.S.A., and Denis Smalley, U.K., will share with their fellows experiences of communication between composer and audience, and will discuss problems of structure and perception. Other participants will include Diana Deutsch, University of California, San Diego, Sören Nielzén, Lund University, and John A. Sloboda, U.K., who will discuss scientific experiences related to problems encountered by composers. This will allow for a dialogue on the structure of sound and music, hearing, and perception.

Leading international figures in the fields of structure analysis, audiology, neurophysiology, the psychology of perception, psychophysiology, and psychiatry have been invited to participate in the Scientific Session, which will begin with a brief survey of current research. Lectures on the structure of electroacoustic sound will be followed by lectures on sound and hearing. The symposium will end with lectures and discussions devoted to the problem of describing complex sounds and the registration of neurophysiological correlates of sound perception.

The Music Festival will include works by Sten Hansson and Charlie Morrow, "Montgolfier Music" for hot-air balloons, lasers, electronic music (Anders Blomqvist and Ảke Parmerud) live, live electronic and trumpet music (Palle Mickelborg and Kenneth Knudsen), and the performance of Leo Nilsson's recently written work for computer and synthesizer.

Further information may be obtained from Experimental Music Research, Department of Musicology, Kävlingevägen 20, 22240 Lund, Sweden (Telephone: 46-46-104734; Electronic mail address: EMRSNZ@SELDC52). 